\title{
The Current Situation and Thought of Chinese Teaching of Painting \\ Yuan Liu
}

Art College of Xi'an University of Arts and Science, 710065

\author{
Keywords: Basis; Specialized course; Cultural accomplishment
}

\begin{abstract}
With the development of society and economy, the life quality and level have been improved. Therefore, many people now begin to focus more on the art and traditional culture. Chinese painting, as the quintessence of Chinese culture, becomes more and more important in the point of development of talents. However, because of the expansion of recruit by many universities, the Chinese painting teaching has been confronted with a number of problems. This essay aims to analyze the current situation and thought of Chinese painting teaching.
\end{abstract}

\section{Introduction}

The fine arts education of higher education with modern significance and style has started from 20 century in China. At that time, a number of scholars walked out of the nation and began to learn the western art. They highly praise the western teaching mode which is based on the realism. After they came back to China, they set up the arts education mode which revolved with the western teaching mode. Since then, the western teaching theory, system and teaching mode had been constantly permeated into the Chinese painting teaching, which became the basis of university education, and gradually developed into the teaching style and pattern of today's universities, which indicated that no matter what major the students have chosen, they need to take an exam of sketching and color before admission. In the first year of university, they will learn some western basic course such as sketching, color, perspective and dissection, and then the specialized course. This kind of art education mode ignores the difference present in Chinese and western painting, which causes a number of problems for Chinese painting teaching.

\section{The Current Situation of Chinese painting Teaching}

\section{Pour Basic Skills of Chinese Painting}

First of all, the students who major in Chinese painting have poor basic skills. In terms of these part of students, to grasp the western basic skills can benefit them to develop. However, to teach the basic skills of Chinese painting with only western basic courses will definitely affect the study of Chinese painting in some extent. In one hand, western basic courses requires most of the students to focus on some western expression way such as the light and shade, somatosensory and perspective during the creation, which ignores the graphics effects and the expressive force of lines in Chinese painting, fails to understand that only by lines can the subject space and somatosensory can be expressed. In another hand, this kind of basic courses and practices result in the lack of ink and pen basis on Chinese painting students and poor calligraphy basis. It misunderstands the color used in Chinese painting as single and lack of express force, even some students know little about the materials of Chinese painting. They can hardly handle the ink brush when they begin to create the work, the problems are the soft and powerless handling the brush and the awful use of the ink. At the same time, this kind of teaching mode barely gets involved with Chinese painting, which leads to the simple and abstract understanding towards Chinese painting by students. Students under this kind of teaching mode have no sense of the ink value and the cultural connotation in Chinese painting. The copying is bored and rigid, the lines lacks power and flexibility. The works of students have neither charm nor profound significance of calligraphy. All the phenomenon represents the poor basic skills of Chinese painting. In addition, the school time is limited, most part of students can hardly transfer the western painting language into Chinese painting language, and then their own painting language for reaching the innovation. Therefore, they must be confused and 
baffled when they study, some of them pursue quick success and instant benefits, for example, some students completely apply western painting mode to create Chinese painting, or stiffly copy the Chinese painting mode, which does no good to the modern development of Chinese painting.

\section{Improper Course Setting}

Today's course setting of Chinese painting generally lacks scientificity and rationality. The practice ability of Chinese painting is important, however, the creation skill is the same. But most students lack the theory courses, they have little understanding of the history of Chinese painting, which will not help them to understand the cultural deposits and connotation. Also, theory courses in many universities contain mainly the general information, the specialized courses is too little. Students can hardly set up the cohesion and sensation with the tradition and history of Chinese painting. Most of the art universities set the specialized courses only for graduate student, such as calligraphy. The lack of specialized courses of Chinese painting affects the study and deep understanding of Chinese painting in a bad way. A piece of work with only skills and without the support of theory and history cannot be the goal for students, even for the arts education of higher education. In addition, except for the ignorance of specialized courses of Chinese painting in universities, students themselves can barely understand the significance to learn the theory. Most of them attend the theory course for only the attendance, they have seldom devoted either time or energy to learn. Therefore, the urgent task for universities and teachers is to improve the current specialized courses setting, add with more specialized courses of Chinese painting. And for those teachers who deeply study Chinese painting, they have one more mission, which is to promote an atmosphere for university and class to study. The addition of specialized courses of Chinese painting can enable the students to deeply understand not only the Chinese painting, but also the cultural connotation. Specialized courses bring a breakthrough for students' creation. Works done based on this can avoid the vain, single and stiff style.

\section{Traditional Teaching Concept}

First of all, the joint examination in major includes sketching and color. These two subjects basically come from west in the point of aesthetic system and painting theory, which have little connection with Chinese painting system. Students who have been selected by this way know nothing about Chinese painting, except for a few part of students who may be really interested in Chinese painting. Most of the students passively select Chinese painting.

Second, in the long term Chinese painting teaching, it goes from copying to sketch from nature, and then to the creation. The teaching materials are divided into three major subjects, which are figures, flower and birds, mountain. Through repeated practice day by day, the entire study effect is improved. However, due to the zero understanding of Chinese painting, students must get through these three stages and subjects in the limited college time, which quietly leads to a phenomenon that student seeks for quick success and benefits. The four-year college studying effect is just a kind of routine for some part of students. If more qualified or even high-level Chinese painting talents need to be trained, objectively speaking, the current situation fails to reach that.

\section{Lack of good Atmosphere for Art}

When taking Chinese painting courses in most of art universities, they always ignore one problem, which is the atmosphere of class. For students who learn art, the atmosphere of class is of great significance in the point of understanding and improving the artistic accomplishments. For example, during the class, the remarks toward the works from a teacher directly affect the attraction and study of students. Bland and stiff remark hardly gets any response from students, which means the atmosphere is bad. Therefore, there should be some activities or lectures about Chinese painting in universities, which facilitates the entire artistic atmosphere of the whole school. In terms of the students, artistic atmosphere directly determines whether or not they choose to learn Chinese 
painting. Many students seek for skills and the final effect of the work. However, blindly seeking for skills will not help the students go in a very long way in Chinese painting. Therefore, good artistic atmosphere can attract more artists to devote themselves into the study of Chinese painting.

\section{Ignorance of Artistic Accomplishments}

Artistic accomplishment is not about the skills and their express way, it is about the accumulated accomplishments. It needs time to diffuse and to see the final effect. However, many students spend most of the time and energy on practicing, they seldom have any ambition or plan for their artistic accomplishment. The artistic accomplishment is also about the accumulation of culture knowledge. Before the university entrance examination, many students take no time or energy to study the basic culture knowledge. The lack of knowledge will also affect the study of Chinese painting since they hardly improve their artistic accomplishment. It is general situation nowadays for most of university students with little knowledge. However, college should pay attention on this problem, and focus on the training of artistic accomplishment. Otherwise, the art of high education will lack the cultural deposits, and this must affect the inheritance and progress of entire Chinese tradition culture and art. Therefore, college and teachers should enhance the culture knowledge training in daily course, unconsciously improve students' artistic accomplishment. The progress in artistic accomplishment for students can be one of the motivations to deeply understand and study Chinese painting. And the accumulation of culture and deposits facilitates the creation of work. Teachers can set many culture courses, and aim to improve their cultural awareness. Due to the lack of culture knowledge before getting into university, schools fail to help students to make a perfect transmit in the point of culture knowledge. Students who lack the theory basis will not be able to improve their creation skills and artistic accomplishment.

\section{Thought of Chinese Painting Teaching}

\section{The Significance of Basic Education}

Chinese painting, as a kind of art, is not only the expression of culture and emotion, but also the demonstration of solid basic skills. If teachers do not take it seriously at the beginning of the study, spend not enough time to practice it, it will be really hard to improve it in the future. Therefore, the basic skills course is the main teaching activities among all the specialized courses in art university. The basic skills of Chinese painting include three aspects. First of all, it is the ability to shape, which means the grasp of body construction and the proportion of athletic anatomy, and professional application of lines. Lines can show vivid image, which is the so-called line drawing. Many noted painters of dynasties had shown enough experience in this aspect. However, to blend the western painting method into the modern basic practice of shaping, which is considered as the auxiliary teaching training for analyzing and studying the painting objects in so many aspects such as decent, level, dark and bright, texture, quantity and sense of space, can improve the understanding of shape and the skills to draw lines. The second aspect is the ability to fast sketch. For example, during the creation of figures, flowers and birds, mountains and lakes, the activity rule of object and how to express it in the work should be all taken into practiced, and the copying and ink application of lines of figures, flowers and birds, mountains and lakes as well. The level of basic skills determines the control and handle of each detail during each creation process. And each detail is finally related to the effect and spirit of the work. In addition, for different application of so many tools, there are different ways to use them. Daily teaching should involve intensive practice of basic skills. Students need to grasp the basic skills and different effect by different pen, ink and paper. Expertly applying the basic skills is the basis for students to express their art accomplishment and cultural deposits. 


\section{The Improvement of Spirit and Cultural Deposits}

The spirit and cultural deposits determine the level of the Chinese painting, which means the crucial effect on the final work is the students 'own accumulation of culture. Taking landscape painting as an example, it is sure that different cultural deposits show different details in the work. It is the fact that artists who seek for high cultural deposits can produce great work that shows the truth to people. Their works can be considered as of great art value. And as for the so-called art value, teachers train the students of the art value. And it is all about how to let them react and response, which means that the student can have a lot in common with the work, it is about that the students are inspired by everything in the world, such as the feeling for the nature, the sense of figures. Each detail tells what students think. To bring what is in their head onto the paper is the best way to form students' own creation style, which is the so-called spirit. The nature rules contain philosophy, which you can always find out if you pay attention to. Teachers should inspire student by feeling the misery of the nature, such as the connection and relation between time and space, universe and life. The biggest difference between Chinese painting and western painting is every work is seeking for the spirit and cultural deposits in Chinese painting. Therefore, teachers should take it seriously to train students' spirit and cultural deposits, train students to understand the meaning of life from the natural philosophy, and how to express and show their experience by the work.

\section{The Improvement of Teaching System}

The study of Chinese painting is different from that of other specialized course. First of all, it is not just about the creation process with ink brush and ink on the paper, that is barely studying of Chinese painting. It is a performance way of art. And the study of art is based on special teaching system. It cannot be prepared by simple teaching materials, neither by fixed creation mode, which will limit the study. In the same way, the performance way and content of art are different as well. Therefore, for the teaching system of Chinese painting, both schools and teachers should work hard on it.

The coverage and content of art are immense. It is a abstract definition. However, Chinese painting belongs to art, and Chinese painting is related to distant history background and traditional culture. It still constantly develops today. The rich content and distant history can both weaken the students' confidence at the very beginning of study. Most of the students hold different basic skills when they get into college, and they have totally different understanding of history and tradition. Under this situation, the understanding of the skills that are addressed by teachers will be different as well. Many students never stop searching for it. Therefore, both teachers and students need a proper education system. For students who major in Chinese painting, the significance to guide is bigger than that of the theory learning. Teachers should also take it seriously to focus on the guidance, outdoor practice and so on. The study of Chinese painting is all about practice and appreciation, comparison, copying and the sense ability towards objects. And all these is hardly accomplished by only theory, or only basic skill, or teaching indoor. The teaching system and content are of great significance above all. Teachers should adjust the class proportion between theory and practice of basic skills. For example, if it takes one semester to learn the theory and professional knowledge, then it will be improper. Teachers need to balance the proportion of the class. In one way, the theory needs to be improved yet in another way, basic skill is keystone as well.

\section{Reference}

[1] Q.Y.Zheng: Theory study of Chinese traditional art education, Vol. 4 (2004) No.4

[2] Y.M.Hu: Emotional function in teaching art in school, Vol. 5 (2005) No.5

[3] H.Y.Wei: Creation and teaching of college about Chinese painting, Vol. 5 (2007) No.5

[4] Z.H.Li: Beauty history, Vol. 5 (2001) No.5

[5] J.X.Peng: General overview of art, Vol. 12 (2002) No.1 
[6] H.X.Wang: Though and strategy of art education in university, Vol. 8 (2005) No.7

[7] Q.Gao: The lack of Chinese traditional culture in Chinese painting teaching , Vol. 11 (2012) No.5, p.86-8

[8] Y.C.Pan: Modern art education history in China, Vol. 7 (2002) No.2 